\title{
CHIMALI 2018: facts and figures
}

\author{
Sauro Vittori ${ }^{1} \cdot$ Marco Arlorio $^{2}$
}

Published online: 29 August 2019

c) Springer-Verlag GmbH Germany, part of Springer Nature 2019

The National Congress of Food Chemistry (CHIMALI series), organized under the patronage of the Interdivisional Group of Food Chemistry (GICA), Italian Chemical Society, is a traditional reference point, primarily for the Italian Food Chemists, but also for the food technologists and for all the professionals interested in the subjects of the Food Chemistry discipline (food composition, identification of new compounds following technological processing of food, characterization of bioactive molecules in food, contaminants, and residues in food, and-more recently - characterization of novel foods, food supplements, and food for special medical purposes).

The themes of the Congress CHIMALI (currently XII edition) were always declined and focused, in particular, to the elucidation of the chemical composition, the quality and safety of typical Italian food products, also encompassing other products from the Mediterranean (or global) area. The XII edition of the Congress, organized in the beautiful Camerino (Macerata, Marche Region), a city shocked by a strong earthquake on the 2016, and currently restarting his normal life with an extreme courage and strength, was a successful event also in relation to the choice to use English as the official language, a choice strongly desired and suggested at European level by the Food Chemistry Division of EuChemS (European Chemical Society, sponsor of the event). In fact, FCD-EuChemS encourage all the organizers of the national congresses of food chemistry to improve cultural exchanges among young researchers within Europe, promoting the internationalization of the discipline. This choice allowed a significant number of European colleagues to participate for

Sauro Vittori

Sauro.vittori@unicam.it

Marco Arlorio

marco.arlorio@uniupo.it

1 School of Pharmacy, University of Camerino, Via S. Agostino, 1, Camerino, Italy

2 Dip. di Scienze del Farmaco, Food Chemistry, Biotechnology and Nutrition Unit, Università del Piemonte Orientale “A. Avogadro", Largo Donegani 2/3, Novara, Italy the whole duration of the congress. Respecting the tradition, the themes of the congress covered all the fields of the sector, in particular confirming an interdisciplinary functional approach to the resolution of the scientific problems faced.

This edition was attended by 193 participants, with $12 \%$ coming from abroad, enjoying 17 invited speakers, 39 oral communications, and 107 poster communications.

Several Food Companies and Analytical Companies supported economically the event, allowing the awarding of prizes and scholarships. In this regard, great attention has been paid by the organizers to the young researchers, to whom they have been bestowed 11 scholarships for free participation (registration and accommodation) in the Congress.

Furthermore, a special prize, consisting of free participation plus 500 Euro, has been awarded in memory of the colleague Filippo Pirisi, recently deceased, to the best publication presented by a young Food Chemistry researcher.

The scientific contributions were presented in eight sessions, i.e., composition, traceability, and food quality; nutraceuticals and botanicals; chemical reactions in food; contamination and food safety; food design; from waste to resource of functional chemicals; innovative analytical techniques in food analysis; EU projects and EFSA: an overview. The scientific approach of the Congress was multitarget, by involving different experts and scientists, who have presented their most recent studies from different points of view, by enhancing the important role of food chemistry in any field related to food world. The first scientific session, "Composition, traceability and food quality", has been focused on the multimethodological approaches used for the characterization and traceability of food and beverages as pepper, oranges, cocoa, pistachio, caper, and wine, and on integrated approach to characterize wheat genotypes. The session "Nutraceuticals and Botanicals" highlighted both the importance to obtain chemically characterized and studied extracts for the production of nutraceuticals from apple, hempseed, propolis, chestnuts, and the biological activity of contained molecules as polyphenols and peptides. The third session, "Chemical reactions in food", presented thermally neo-formed compounds during food digestion, the 
functionalization of milk proteins by nanostructures, and the effect of heating on the formation of ginkgotoxin. The session dedicated to "Contamination and food safety" highlighted the importance of monitoring the presence of mycotoxins in food according to the EU guidelines, the allergenic cross reactivity of shrimp, and the toxicological risk of silver nanoparticles in hydroponic culture. The "Food Design" session revealed the new contents in this field, underlining the important role of designing food in the evaluation of bioaccessibility and digestibility of nutrients. The session "From waste to resources of functional chemicals" highlighted the importance to consider the waste of food matrices as source of bioactives, especially considering the concept of circular bioeconomy, underlining that cooking oils, olive mill, pomegranate, and others can be considered resources of chemicals. In the session "Innovative analytical techniques", modern approaches to food analysis have been presented, including the use of bi-dimensional chromatography, the evolution of mass spectrometry, the electron spin resonance, and the electronic eye and tongue. Finally, the session "EU projects and EFSA" presented some financed projects on the field with a special eye on food supplements containing botanicals.

Even considering the large number of events related to food chemistry currently organized in Italy and in Europe, the CHIMALI Congress confirmed its usefulness and its crucial function on the national soil, expanding its value also at international level. The Executive Board of the Interdisciplinary Group of Food Chemistry of the Italian
Chemical Society (GICA-SCI) and the Executive Board of the Food Chemistry Division of EuChemS hope that many other national congresses (following the example of the one organized in Budapest in 2017, and the CHIMALI in 2018) will pursue the choice to share the knowledge setting at least a part of the congress in English language, allowing to create a European "melting pot" useful for sharing new researches in food chemistry field.

Hoping to couple science with the pleasure of sharing culture, food, and traditions of each single country.

Prof. Marco Arlorio-Past Coordinator of GICA-SCI; President of the Executive Board of Food Chemistry Division-EuChemS

Prof. Sauro Vittori-Chair of the Organizing Committee of CHIMALI 2018, XII edition

\section{Compliance with ethical standards}

Conflict of interest Both authors declare no conflict of interests.

Compliance with ethics requirements This article does not contain any studies with human or animal subjects.

Publisher's Note Springer Nature remains neutral with regard to jurisdictional claims in published maps and institutional affiliations. 